\title{
CRÓNICA PARLAMENTARIA DEL SENADO
}

Mํㅡㄴ VICTORIA GARCÍA-ATANCE GARCÍA DE MORA

Profesora Titular Derecho Constitucional 


\section{SUMARIO}

A) Competencia Normativa. A.l. Actividad legislativa: A.l.1. De iniciativa popular. A.I.2. Proyectos de Ley.A.I.3. Proposiciones de Ley. a) De iniciativa de los grupos parlamentarios del Senado. b) Iniciativa del Congreso de los Diputados. A.I.4. Tratados y Convenios Internacionales (art. 94.1.CE). A.ll. Actividad financiera. B) COMPETENCIA DE CONTROL. B.I. Mociones en Comisión. B.II. Mociones ante el Pleno. B.III. Interpelaciones. B.IV. Mociones consecuencia de interpelaciones. B.V. Preguntas orales en Pleno. B.VI. Preguntas orales en Comisión. Preguntas orales en Comisión Mixta formuladas por Diputados. B.VII. Preguntas con respuesta escrita. C) Competencias electivas. Elección del Defensor del Pueblo. D) Declaración institucional. E) Relaciones con órganos e instituciones PÚBLICAS: E.I. Con el Tribunal Constitucional. E.I.1. Recurso de Inconstitucionalidad. E.I.2. Cuestión de inconstitucionalidad. E.II. Con el Poder Judicial. E.Il.1. Memoria del Consejo General del Poder Judicial. E.II.2. Otras manifestaciones de relación con el Consejo General del Poder Judicial. E.Il.3. Otros asuntos relacionados con órganos jurisdiccionales. E.III. Con el Tribunal de Cuentas. E.III.1. Informe sobre la cuenta general del Estado. E.III.2. Otros informes del Tribunal de Cuentas. E.III.3. Otras manifestaciones de relación con el Tribunal de Cuentas. E.IV. Con el Defensor del Pueblo. E.IV.1. Otros informes del Defensor del Pueblo. E.V. Relación con órganos de las Comunidades Autónomas. F) RelacioNeS INTERNACIONALES: F.I. Unión interparlamentaria. F.ll. Asamblea Parlamentaria del Consejo de Europa. F.III. Otras instituciones parlamentarias internacionales. 


\title{
CRÓNICA PARLAMENTARIA DEL SENADO
}

\author{
POR \\ Mª VICTORIA GARCÍA-ATANCE GARCÍA DE MORA \\ Profesora Titular de Derecho Constitucional
}

La crónica del Senado que contemplamos en el presente número de nuestra Revista abarca el $2 .^{\circ}$ período de sesiones de 1999 de la VI Legislatura que acaba de finalizar, con la convocatoria de nuevas elecciones, a través del Real Decreto 64/2000, publicado en el BOE de 18 de enero de 2000.

\section{A) COMPETENCIA NORMATIVA}

\section{A.I. Actividad legislativa}

\section{A.I.1. De iniciativa popular}

\section{Iniciativa legislativa popular}

Procedimiento: Ordinario.

Fecha de presentación: 27/12/99.

Autores: García Villamuriel, Luis, y otros.

Objeto: Proposición de Ley de medidas preventivas contra la intervención de mano de obra infantil en la elaboración de productos de importación.

Situación actual: Concluido (Tramitado) en fecha 20 Ene 2000 


\section{A.1.2. Actividad legislativa de Proyectos de Ley}

De los 26 Documentos que reflejan Proyectos de Ley presentados por el Gobierno, vamos a reseñar algunos de los más significativos del presente período de sesiones, que se extiende desde septiembre de 1999 hasta diciembre de 1999.

\section{Proyecto de Ley}

Procedimiento: Urgente.

Fecha de presentación: 10/09/99.

Autor: Congresos de los Diputados.

Objeto: Proyecto de Ley de ordenación de la edificación.

Situación actual: Concluido (Aprobado con modificaciones) en fecha 29 Sep 1999.

Comisión competente: Comisión de Obras Públicas, Medio Ambiente, Transportes y Comunicaciones.

Procedimiento: Urgente.

Fecha de presentación: 10/09/99.

Autor: Congresos de los Diputados

Objeto: Proyecto de Ley para promover la conciliación de la vida familiar y laboral de las personas trabajadoras.

Situación actual: Concluido (Aprobado con modificaciones) en fecha 29 Sep 1999.

Comisión competente: Comisión de Trabajo y Seguridad Social.

Procedimiento: Ordinario.

Fecha de presentación: 17/09/99..

Autor: Congresos de los Diputados.

Objeto: Proyecto de Ley por la que se modifica la Ley 38/1988, de 28 de diciembre, de Demarcación y de Planta Judicial.

Situación actual: Concluido (Aprobado sin modificaciones) en fecha 20 Oct 1999.

Comisión competente: Comisión de Justicia. 
Procedimiento: Ordinario.

Fecha de presentación: 2/10/99.

Autor: Congreso de los Diputados.

Objeto: Proyecto e Ley por la que se modifica la Ley 13/1995, de 18 de mayo, de Contratos de las Administraciones Públicas.

Situación actual: Concluido (Aprobado con modificaciones) en fecha 02 Dic 1999.

Comisión competente: Comisión de Interior y Función Pública.

Procedimiento: Ordinario.

Fecha de presentación: 5/10/99.

Autor: Congreso de los Diputados.

Objeto: Proyecto de Ley de Enjuiciamiento Civil.

Situación actual: Concluido (Aprobado con modificaciones) en fecha 02 Dic 1999.

Comisión competente: Comisión de Justicia.

Procedimiento: Ordinario.

Fecha de presentación: 6/10/99.

Autor: Congreso de los Diputados.

Objeto: Proyecto de Ley Orgánica de Protección de Datos (antes denominado Proyecto de Ley Orgánica de protección de datos de carácter personal).

Situación actual: Concluido (Aprobado con modificaciones) en fecha 18 Nov 1999.

Comisión competente: Comisión Constitucional.

Procedimiento: Urgente.

Fecha de presentación: 15/10/99.

Autor: Congreso de los Diputados.

Objeto: Proyecto de Ley sobre el desplazamiento de trabajadores en el marco de una prestación de servicios transnacional.

Situación actual: Concluido (Aprobado sin modificaciones) en fecha 03 Nov 1999.

Comisión competente: Comisión de Trabajo y Seguridad Social. 
Procedimiento: Urgente.

Fecha de presentación: 12/11/99.

Autor: Congreso de los Diputados.

Objeto: Proyecto de Ley de reforma de la Ley 16/1989, de 17 de julio, de Defensa de la Competencia.

Situación actual: Concluido (Aprobado con modificaciones) en fecha 02 Dic 1999.

Comisión competente: Comisión de Economía y Hacienda.

Procedimiento: Ordinario.

Fecha de presentación: 17/11/99.

Autor: Congreso de los Diputados.

Objeto: Proyecto de Ley Orgánica reguladora de la responsabilidad penal de los menores.

Situación actual: Concluido (Aprobado con modificaciones) en fecha 16 Dic 1999.

Comisión competente: Comisión de Justicia.

Procedimiento: Ordinario.

Fecha de presentación: 25711/99.

Autor: Congreso de los Diputados.

Objeto: Proyecto de Ley de régimen jurídico de la protección de las obtenciones vegetales.

Situación actual: Concluido (Aprobado sin modificaciones) en fecha 17

Dic 1999.

Comisión competente: Comisión de Agricultura, Ganadería y Pesca.

Procedimiento: Urgente.

Fecha de presentación:30/11/99.

Autor: Congreso de los Diputados.

Objeto: Proyecto de Ley Orgánica de modificación de la Ley Orgánica 10/1995, de 23 de noviembre, del Código Penal, en materia de lucha contra la corrupción de agentes públicos extranjeros en las transacciones comerciales internacionales.

Situación actual: Concluido (Aprobado con modificaciones) en fecha 16 Dic 1999.

Comisión competente: Comisión de Justicia. 
Procedimiento: Urgente.

Fecha de presentación: 30/11/99.

Autor: Congreso de los Diputados.

Objeto: Proyecto de Ley Orgánica de modificación de la Ley Orgánica 10/1995, de 23 de noviembre, del Código Penal, en materia de prohibición del desarrollo y el empleo de armas químicas.

Situación actual: Concluido (Aprobado sin modificaciones) en fecha 17 Dic 1999.

Comisión competente: Comisión de Justicia.

Procedimiento: Urgente.

Fecha de presentación: 1/12/99.

Autor: Comisión Constitucional.

Objeto: Proyecto de Ley Orgánica de modificación de la Ley Orgánica 2/1979, de 3 de octubre, del Tribunal Constitucional.

Situación actual: Concluido (Aprobado sin modificaciones) en fecha 16 Dic 1999.

Comisión competente: Comisión Constitucional.

Procedimiento: Urgente.

Fecha de presentación: 18/12/99.

Autor: Congreso de los Diputados.

Objeto: Proyecto de Ley Orgánica de modificación de la Ley Orgánica 10/1995, de 23 de noviembre, del Código Penal, en materia de delitos de terrorismo.

Situación actual: Concluido (Caducado) en fecha 18 Ene 2000.

Comisión competente: Comisión de Justicia.

\section{A.I.3. Proposiciones de Ley}

a) De iniciativa de los Grupos Parlamentarios del Senado

Proposición de Ley de Grupos Parlamentarios del Senado

Procedimiento: Ordinario.

Fecha de presentación: 21/09/99. 
Autor: Grupo Parlamentario Mixto.

Objeto: Proposición de Ley de modificación del artículo 91 de la Ley 37/1992, de 28 de diciembre, del Impuesto sobre el Valor Añadido (IVA).

Situación actual: Concluido (Rechazado) en fecha 30 Nov 1999.

Procedimiento: Ordinario.

Fecha de presentación: 2/12/99.

Autor: Grupo Parlamentario Socialista.

Objeto: Proposición de Ley de modificación de la Ley 3/1999, de 11 de enero, por la que se crea el Parque Nacional de Sierra Nevada.

Situación actual: Concluido (Caducado) en fecha 18 Ene 2000.

\section{b) Iniciativa del Congreso de los Diputados}

Proposición de Ley del Congreso de los Diputados

Procedimiento: Un mes

Fecha de presentación: 21/09/99.

Autor: Congreso de los Diputados.

Objeto: proposición de Ley de solidaridad con las víctimas del terrorismo.

Situación actual: Concluido (Aprobado sin modificaciones) en fecha 29 Sep 1999.

Comisión competente: Comisión Constitucional.

Procedimiento: Urgente.

Fecha de presentación: 29/11/99.

Autor: Congreso de los Diputados.

Objeto: Proposición de Ley Orgánica sobre derechos y libertades de los extranjeros en España y su integración social.

Situación actual: Concluido (Aprobado con modificaciones) en fecha 16 Dic 1999.

Comisión competente: Comisión Constitucional.

Procedimiento: Ordinario.

Fecha de presentación: 29/11/99. 
Autor: Congreso de los Diputados.

Objeto: Proposición de Ley de creación del Colegio Profesional de Pedagogos.

Situación actual: Concluido (Caducado) en fecha 18 Ene 2000.

Comisión competente: Comisión de Educación y Cultura.

A.I.4. Tratados y Convenios internacionales (art. 94.1. CE)

Autorización de Convenios Internacionales (artículo 94.1 de la Constitución)

Procedimiento: Ordinario.

Fecha de presentación: 7/10/99.

Autor: Congreso de los Diputados.

Objeto: Convenio sobre cooperación para la protección y el aprovechamiento sostenible de las aguas de las cuencas hidrográficas hispano-portuguesas, hecho en Albufeira el 30 de noviembre de 1998.

Situación actual: Concluido (Aprobado) en fecha 16 Nov 1999.

Comisión competente: Comisión de Asuntos Exteriores.

Procedimiento: Ordinario.

Fecha de presentación: 7/10/99.

Autor: Congreso de los Diputados.

Objeto: Protocolo adicional al Acuerdo entre la República Federal de Alemania, la República de Austria, el Reino de Bélgica, el Reino de Dinamarca, el Reino de España, la República de Finlandia, la República Helénica, Irlanda, la República Italiana, el Gran Ducado de Luxemburgo, el Reino de los Países Bajos, la República Portuguesa, el Reino de Suecia, la Comunidad Europea de la Energía Atómica y el Organismo Internacional de Energía Atómica para la aplicación de los párrafos 1) y 4) del artículo III del Tratado sobre la no proliferación de las armas nucleares, adoptado en Viena el 11 de junio de 1998.

Situación actual: Concluido (Aprobado) en fecha 16 Nov 1999.

Comisión competente: Comisión de Asuntos Exteriores. 
Procedimiento: Ordinario.

Fecha de presentación: 7/10/99.

Autor: Congreso de los Diputados.

Objeto: Protocolo, hecho en Copenhague el 17 de marzo de 1999, por el que se modifica el Convenio entre España y Dinamarca para evitar la doble imposición en materia de impuestos sobre la renta $y$ sobre el patrimonio, hecho en Copenhague el 3 de julio de 1972.

Situación actual: Concluido (Aprobado) en fecha 30 Nov 1999.

Comisión competente: Comisión de Asuntos Exteriores.

Procedimiento: Ordinario.

Fecha de presentación: 7/10/99.

Autor: Congreso de los Diputados.

Objeto: Acuerdo entre la Organización Europea de Patentes, la Oficina Española de Patentes y Marcas y la Oficina Sueca de Patentes y Registros, sobre el establecimiento de una cooperación en materia de búsquedas internacionales, hecho en Madrid el 10 de febrero de 1999.

Situación actual: Concluido (Aprobado) en fecha 16 Nov 1999.

Comisión competente: Comisión de Asuntos Exteriores.

Procedimiento: Ordinario.

Fecha de presentación: 27/10/99.

Autor: Congreso de los Diputados.

Objeto: Convenio celebrado con arreglo al artículo K.3 del Tratado de la Unión Europea, sobre la competencia, el reconocimiento y la ejecución de resoluciones judiciales en materia matrimonial, hecho en Bruselas el 28 de mayo de 1998, y Declaraciones que efectuará España al mismo.

Situación actual: Concluido (Aprobado) en fecha 30 Nov 1999.

Comisión competente: Comisión de Asuntos Exteriores.

Procedimiento: Ordinario.

Fecha de presentación: 27/10/99.

Autor: Congreso de los Diputados. 
Objeto: Protocolo celebrado con arreglo al artículo K.3 del Tratado de la Unión Europea, relativo a la interpretación por el Tribunal de Justicia de las Comunidades Europeas del Convenio sobre la competencia, el reconocimiento y la ejecución de resoluciones judiciales en asuntos matrimoniales, hecho en Bruselas el 28 de mayo de 1998, y Declaraciones que efectuará España al mismo.

Situación actual: Concluido (Aprobado) en fecha 30 Nov 1999.

Comisión competente: Comisión de Asuntos Exteriores.

Procedimiento: Ordinario.

Fecha de presentación: 27/10/99.

Autor: Congreso de los Diputados.

Objeto: Segundo Protocolo establecido sobre la base del artículo K.3 del Tratado de la Unión Europea, del Convenio relativo a la protección de los intereses financieros de las Comunidades Europeas, hecho en Bruselas el 19 de junio de 1997, y Reserva que formulará España al mismo.

Situación actual: Concluido (Aprobado) en fecha 30 Nov 1999.

Comisión competente: Comisión de Asuntos Exteriores.

Procedimiento: Ordinario.

Fecha de presentación: 27/10/99.

Autor: Congreso de los Diputados.

Objeto: Protocolo de enmienda a la Carta Social Europea, hecho en Turín el 21 de octubre de 1991.

Situación actual: Concluido (Aprobado) en fecha 30 Nov 1999.

Comisión competente: Comisión de Asuntos Exteriores.

Procedimiento: Ordinario.

Fecha de presentación: 27/10/99.

Autor: Congreso de los Diputados.

Objeto: Protocolo establecido sobre la base del artículo K.3 del Tratado de la Unión Europea, del Convenio relativo a la protección de los intereses financieros de las Comunidades Europeas, hecho en Dublín el 27 de septiembre de 1996. 
Situación actual: Concluido (Aprobado) en fecha 30 Nov 1999.

Comisión competente: Comisión de Asuntos Exteriores.

Procedimiento: Ordinario.

Fecha de presentación: 27/10/99.

Autor: Congreso de los Diputados.

Objeto: Protocolo establecido sobre la base del artículo K.3 del Tratado de la Unión Europea, relativo a la interpretación, con carácter prejudicial por el Tribunal de Justicia de las Comunidades Europeas, del Convenio sobre la protección de los intereses financieros de las Comunidades Europeas, y Declaración relativa a la adopción simultánea del Convenio sobre la protección de los intereses financieros de las $\mathrm{Co}$ munidades Europeas y del Protocolo relativo a la interpretación con carácter prejudicial, por el Tribunal de Justicia de las Comunidades Europeas, de dicho Convenio, hechos en Bruselas el 29 de noviembre de 1996, y Declaraciones que efectuará España a aquél.

Situación actual: Concluido (Aprobado) en fecha 30 Nov 1999.

Comisión competente: Comisión de Asuntos Exteriores.

Procedimiento: Ordinario.

Fecha de presentación: 27/10/99.

Autor: Congreso de los Diputados.

Objeto: Convenio establecido sobre la base de la letra c) del apartado 2 del artículo K.3 del Tratado de la Unión Europea, relativo a la lucha contra los actos de corrupción en los que estén implicados funcionarios de las Comunidades Europeas o de los Estados Miembros de la Unión Europea, firmado en Bruselas el 26 de mayo de 1997, así como Reserva y Declaración que España va a formular al mismo.

Situación actual: Concluido (Aprobado) en fecha 30 Nov 1999.

Comisión competente: Comisión de Asuntos Exteriores.

Procedimiento: Ordinario.

Fecha de presentación: 27/10/99.

Autor: Congreso de los Diputados.

Objeto: Protocolo Adicional a la Carta Social Europea, hecho en Estrasburgo el 5 de mayo de 1998. 
Situación actual: Concluido (Aprobado) en fecha 30 Nov 1999.

Comisión competente: Comisión de Asuntos Exteriores.

Procedimiento: Ordinario.

Fecha de presentación: 27/10/99.

Autor: Congreso de los Diputados.

Objeto: Protocolo Adicional al Convenio para la protección de los derechos humanos y la dignidad del ser humano con respecto a las aplicaciones de la biología y la medicina, por el que se prohibe la clonación de seres humanos, hecho en París el 12 de enero de 1998.

Situación actual: Concluido (Aprobado) en fecha 30 Nov 1999.

Comisión competente: Comisión de Asuntos Exteriores.

Procedimiento: Ordinario.

Fecha de presentación: 3/12/99.

Autor: Congreso de los Diputados.

Objeto: Convenio establecido sobre la base del artículo K.3 del Tratado de la Unión Europea, sobre las decisiones de privación del derecho de conducir, hecho en Bruselas el 17 de junio de 1998, así como Declaraciones que España va a formular al mismo.

Situación actual: Concluido (Caducado) en fecha 18 Ene 2000.

Comisión competente: Comisión de Asuntos Exteriores.

\section{A.II. Actividad Financiera}

\section{Proyecto de Ley}

Procedimiento: Urgente.

Fecha de presentación: 10/09/99.

Autor: Congreso de los Diputados.

Objeto: Proyecto de Ley sobre sistemas de pagos y de liquidación de valores.

Situación actual: Concluido (Aprobado con modificaciones) en fecha 29 Sep 1999.

Comisión competente: Comisión de Economía y Hacienda. 
Procedimiento: Ordinario.

Fecha de presentación: 15/11/99.

Autor: Congreso de los Diputados.

Objeto: Proyecto de Ley sobre concesión de un crédito extraordinario por importe de 231.898 .349 pesetas, para abonar a Alvamar, S.A. la indemnización derivada de las sentencias del Tribunal Supremo de 27 de junio de 1994 y 6 de noviembre de 1997.

Situación actual: Concluido (Aprobado sin modificaciones) en fecha 02 Dic 1999.

Comisión competente: Comisión de Presupuestos.

Procedimiento: Un mes

Fecha de presentación: 23/11/99.

Autor: Congreso de los Diputados.

Objeto: Proyecto de Ley de Presupuestos Generales del Estado para el año 2000.

Situación actual: Concluido (Aprobado con modificaciones) en fecha 16 Dic 1999.

Comisión competente: Comisión de Presupuestos.

Procedimiento: Un mes

Fecha de presentación: 23/11/99.

Autor: Congreso de los Diputados.

Objeto: Proyecto de Ley de Medidas Fiscales, Administrativas y del Orden Social.

Situación actual: Concluido (Aprobado con modificaciones) en fecha 14 Dic 1999.

Comisión competente: Comisión de Economía y Hacienda.

\section{B) COMPETENCIA DE CONTROL}

\section{B.I. Mociones en Comisión}

De las 29 Mociones en Comisión presentadas como una manifestación de la competencia de control de la Cámara, procederemos a reseñar aquéllas que juzgamos más relevantes. 


\section{Moción en Comisión}

Procedimiento: Ordinario.

Fecha de presentación: 9/09/99.

Autor: Grupo Parlamentario Socialista.

Objeto: Moción por la que se insta al Ministerio de Fomento a que llegue a un acuerdo con la Junta de Andalucía y la compañía concesionaria de la autopista A-4 para la liberación del peaje de la misma.

Situación actual: Concluido (Rechazado) en fecha 28 Oct 1999.

Comisión competente: Comisión de Obras Públicas, Medio Ambiente, Transportes y Comunicaciones.

Procedimiento: Ordinario.

Fecha de presentación: 15/09/99.

Autor: Grupo Parlamentario Socialista.

Objeto: Moción por la que se insta al Gobierno a que, en colaboración con el Consejo de Gobierno de La Rioja, ponga en marcha un programa integral de actuaciones que impulse el desarrollo potencial del área de influencia de San Millán de la Cogolla (La Rioja), declarado Patrimonio de la Humanidad.

Situación actual: Concluido (Caducado) en fecha 18 Ene 2000.

Comisión competente: Comisión de Economía y Hacienda.

Procedimiento: Ordinario.

Fecha de presentación: 28/09/99.

Autor: Grupo Parlamentario Socialista.

Objeto: Moción por la que se insta al Gobierno a presentar, antes de finales de 1999, un plan detallado de actuación para dar cumplimiento al convenio suscrito entre el Ministerio de Fomento y la Diputación Foral de Álava, y solucionar los problemas existentes en el tramo de la carretera nacional $\mathrm{N}-\mathrm{I}$ a su paso por Condado de Treviño (Burgos) conocido como la Legua del Rey.

Situación actual: Concluido (Rechazado) en fecha 28 Oct 1999.

Comisión competente: Comisión de Obras Públicas, Medio Ambiente, Transportes y Comunicaciones. 
Procedimiento: Ordinario.

Fecha de presentación: 1/10/99.

Autor: Grupo Parlamentario Socialista.

Objeto: Moción por la que se insta al Gobierno a que, en el plazo más breve posible, apruebe la creación de una Comisaría de Policía Nacional en la ciudad de Chiclana de la Frontera (Cádiz), dotándola de los medios técnicos y humanos necesarios para el desempeño de sus funciones.

Situación actual: Concluido (Caducado) en fecha 18 Ene 2000.

Comisión competente: Comisión de Interior y Función Pública.

Procedimiento: Ordinario.

Fecha de presentación: 5/10/99.

Autor: Grupo Parlamentario Socialista.

Objeto: Moción por la que se insta al Gobierno a aplicar, con carácter de urgencia, el Plan de Fomento Especial de las Energías Renovables.

Situación actual: Concluido (Caducado) en fecha 18 Ene 2000.

Comisión competente: Comisión de Industria, Comercio y Turismo.

Procedimiento: Ordinario.

Fecha de presentación: 8/10/99.

Autor: Grupo Parlamentario Popular en el Senado.

Objeto: Moción por la que la Comisión Constitucional acuerda la creación en su seno de una Ponencia de estudio sobre la intolerancia y las nuevas formas de esclavitud y marginación en nuestra sociedad.

Situación actual: Concluido (Aprobado sin modificaciones) en fecha 18 Oct 1999.

Comisión competente: Comisión Constitucional.

Procedimiento: Ordinario.

Fecha de presentación: 20/10/99.

Autor: Grupo Parlamentario Socialista.

Objeto: Moción por la que se insta al Gobierno a que modifique la normativa española sobre jornadas laborales especiales y a que defienda la modificación de la normativa comunitaria a fin de que ambas posibiliten un límite absoluto de cuarenta y ocho horas 
semanales de trabajo para todos los conductores profesionales, así como a que adopte otras medidas para que la profesión de conductor deje de ser una profesión de riesgo.

Situación actual: Concluido (Aprobado) en fecha 21 Dic 1999.

Comisión competente: Comisión de Obras Públicas, Medio Ambiente, Transportes y Comunicaciones.

Procedimiento: Ordinario.

Fecha de presentación: 21/10/99.

Autor: Grupo Parlamentario Socialista.

Objeto: Moción por la que se insta al Gobierno a que impulse, en el seno del Consejo de Ministros de la Unión Europea, acciones conjuntas de este organismo tendentes a prestar todo el apoyo a aquellos ciudadanos europeos condenados a muerte para que las ejecuciones no lleguen a producirse, así como a que traslade a dicho Consejo la necesidad de fomentar la presentación y apoyo en favor de una moratoria universal de las ejecuciones, con vistas a la abolición de la pena de muerte.

Situación actual: Concluido (Aprobado con modificaciones) en fecha 25 Nov 1999.

Comisión competente: Comisión de Asuntos Exteriores.

Procedimiento: Ordinario.

Fecha de presentación: 8/11/99.

Autor: Grupo Parlamentario Socialista.

Objeto: Moción por la que se insta al Gobierno a que vigile el estricto cumplimiento de la legislación laboral en materia de regulación de empleo y de reestructuración de empresas, ante el anuncio del cese de la actividad en la factoría que la empresa multinacional Carrier España tiene en Guadalajara.

Situación actual: Concluido (Aprobado sin modificaciones) en fecha 09 Dic 1999.

Comisión competente: Comisión de Trabajo y Seguridad Social.

Procedimiento: Ordinario.

Fecha de presentación: 8/11/99.

Autor: Grupo Parlamentario Socialista. 
Objeto: Moción por la que se insta al Ministerio del Interior a que, de manera inmediata, adopte las medidas y prevea las partidas necesarias para adecuar los depósitos carcelarios, consiguiendo que reúnan las condiciones necesarias para poder realizar en ellos los arrestos de fin de semana en condiciones satisfactorias.

Situación actual: Concluido (Caducado) en fecha 18 Ene 2000.

Procedimiento: Ordinario.

Fecha de presentación: 10/11/99.

Autor: Grupo Parlamentario Socialista.

Objeto: Moción por la que se insta al Gobierno a ampliar el número de magistrados adscritos a la sección de la Audiencia Provincial de Vigo hasta alcanzar, lo antes posible, el número inicialmente proyectado de cinco magistrados.

Situación actual: Concluido (Rechazado) en fecha 21 Dic 1999.

Comisión competente: Comisión de Justicia.

Procedimiento: Ordinario.

Fecha de presentación: 16/12/99.

Autor: Grupo Parlamentario Popular en el Senado.

Objeto: Moción por la que se insta al Gobierno a apoyar, desarrollar y difundir nacional e internacionalmente el papel de la Fundación de San Millán de la Cogolla.

Situación actual: Concluido (Caducado) en fecha 18 Ene 2000.

\section{B.II. Mociones ante el Pleno}

\section{Moción ante el Pleno}

Procedimiento: Ordinario.

Fecha de presentación: 16/09/99.

Autor: Grupo Parlamentario Catalán en el Senado de Convergencia I Unió.

Objeto: Moción por la que se insta al Gobierno a que en los trenes de largo recorrido de la Red Nacional de los Ferrocarriles Españoles (RENFE) que atraviesen territorios con diversas lenguas oficiales los anuncios que se realicen a través de altavoz sean pronunciados en dichas lenguas. 
Situación actual: Concluido (Aprobado sin modificaciones) en fecha 28 Sep 1999.

Procedimiento: Ordinario.

Fecha de presentación: 20/09/99.

Autor: Grupo Parlamentario Socialista.

Objeto: Moción por la que se insta al Gobierno a establecer la estación de Sagrera, en Barcelona, como estación intermodal del tren de alta velocidad (AVE) entre Madrid, Barcelona y la frontera francesa.

Situación actual: Concluido (Rechazado) en fecha 28 Sep 1999.

Procedimiento: Ordinario.

Fecha de presentación: 20/09/99.

Autor: Grupo Parlamentario Popular en el Senado.

Objeto: Moción por la que se insta a las Comunidades Autónomas a que eviten adoptar medidas relacionadas con el sistema de pensiones que, fuera de su ámbito competencial, puedan poner en riesgo la existencia de un sistema público de pensiones que garantice la igualdad de trato de los españoles en todo el territorio nacional.

Situación actual: Concluido (Aprobado sin modificaciones) en fecha 28 Sep 1999.

Procedimiento: Ordinario.

Fecha de presentación: 27/09/99.

Autor: Grupo Parlamentario Socialista.

Objeto: Moción por la que se insta al Gobierno al inmediato cumplimiento de las mociones aprobadas por el Pleno del Senado que tienen por objeto colaborar en el impulso de la actividad propia de la Comisión General de las Comunidades Autónomas, así como aquellas otras que inciden directamente en el desarrollo autonómico; y por la que se insta a la Comisión General de las Comunidades Autónomas para que, de forma inmediata, cumpla los acuerdos tomados por el Pleno a lo largo de esta Legislatura.

Situación actual: Concluido (Rechazado) en fecha 05 Oct 1999. 
Procedimiento: Ordinario.

Fecha de presentación: 11/10/99.

Autor: Grupo Parlamentario Popular en el Senado.

Objeto: Moción por la que el Senado insta al Gobierno a que, en el marco de sus competencias y a través del Consejo Interterritorial de Salud, impulse las medidas necesarias para mejorar las condiciones en que se usan y se consumen los medicamentos antibióticos en España.

Situación actual: Concluido (Aprobado sin modificaciones) en fecha 19 Oct 1999.

Procedimiento: Ordinario.

Fecha de presentación: 25/10/99.

Autor: Grupo Parlamentario Socialista.

Objeto: Moción por la que se insta al Gobierno a que adopte las medidas necesarias para que las Cajas de Ahorros destinen un porcentaje de sus beneficios a la concesión de umini créditos blandos" en intereses y amparados en un mecanismo rápido y efectivo de concesión.

Situación actual: Concluido (Rechazado) en fecha 02 Nov 1999.

Procedimiento: Ordinario.

Fecha de presentación: 29/10/99.

Autores: Grupo Parlamentario Popular en el Senado. Grupo Parlamentario Socialista. Grupo Parlamentario de Senadores Socialistas Vascos. Grupo Parlamentario Catalán en el Senado de Convergencia I Unió. Grupo Parlamentario Mixto.

Objeto: Moción por la que el Senado de España respalda y hace suya la Resolución 1999/61, aprobada el 25 de abril de 1999 por la Comisión de Derechos Humanos de las Naciones Unidas y, en consecuencia, aboga por la suspensión de las ejecuciones de las sentencias de muerte y por la moratoria universal de las mismas, y solicita que todos los países se sumen a dicha Resolución.

Situación actual: Concluido (Aprobado sin modificaciones) en fecha 02 Nov 1999.

Procedimiento: Ordinario.

Fecha de presentación: 8/11/99. 
Autor: Grupo Parlamentario Popular en el Senado.

Objeto: Moción por la que se insta al Gobierno a promover que los hijos de emigrantes españoles obtengan la nacionalidad española.

Situación actual: Concluido (Aprobado con modificaciones) en fecha 16 Nov 1999.

Procedimiento: Ordinario.

Fecha de presentación: 22/11/99.

Autor: Grupo Parlamentario Socialista.

Objeto: Moción por la que se declara que la consolidación de las expectativas de paz $y$ valores democráticos requiere la renuncia $y$ la condena de los ataques, sabotajes y demás fenómenos que constituyen la llamada violencia callejera como medio para conseguir reivindicaciones políticas, por la que se exige a los grupos $y$ organizaciones que planean $y$ realizan tales acciones el cese inmediato de las mismas, y por la que se insta al Gobierno a la adopción de diversas medidas a este respecto.

Situación actual: Concluido (Aprobado con modificaciones) en fecha 30 Nov 1999.

Procedimiento: Ordinario.

Fecha de presentación: 29/11/99.

Autores: Grupo Parlamentario Popular en el Senado. Grupo Parlamentario Socialista. Grupo Parlamentario de Senadores Socialistas Vascos. Grupo Parlamentario Catalán en el Senado de Convergencia I Unió. Grupo Parlamentario Mixto.

Objeto: Moción por la que se insta al Gobierno para que, en la proximidad de la fecha que se señale para celebrar las elecciones generales, se lleve a cabo una campaña específica, institucional y explicativa sobre la forma de utilizar la papeleta oficial que en cada provincia se apruebe para elegir los Senadores.

Situación actual: Concluido (Aprobado sin modificaciones) en fecha 30 Nov 1999.

\section{B.III. Interpelaciones}

Procedemos a presentar una sucinta relación de entre las 22 interpelaciones presentadas en el Pleno del Senado. 


\section{Interpelación}

Procedimiento: Ordinario.

Fecha de presentación: 6/09/99.

Autor: Gibert I Bosch, Arseni (GPS)

Objeto: Interpelación sobre las carencias y limitaciones de la política del Gobierno para contener la inflación.

Situación actual: Concluido (Formulado Pleno) en fecha 15 Sep 1999.

Procedimiento: Ordinario.

Fecha de presentación: 22/09/99.

Autor: Gangoitti Llaguno, Jon (GPSNV)

Objeto: Interpelación sobre las previsiones del Gobierno con respecto al cumplimiento del mandato del Congreso de los Diputados y del Senado relativo a la participación de las Comunidades Autónomas en los Consejos de Ministros de la Unión Europea.

Situación actual: Concluido (Retirado) en fecha 27 Sep 1999.

Procedimiento: Ordinario.

Fecha de presentación: 27/09/99.

Autor: Gibert I Bosch, Arseni (GPS)

Objeto: Interpelación sobre los análisis presentes y prospectivos, los proyectos y previsiones de actuación y, en definitiva, la orientación general que ha inspirado e inspira al Gobierno en la definición y ejecución de su política en materia de turismo.

Situación actual: Concluido (Formulado Pleno) en fecha 06 Oct 1999.

Procedimiento: Ordinario.

Fecha de presentación: 11/10/99.

Autor: Varela I Serra, Josep (GPCIU)

Objeto: Interpelación sobre las líneas directrices de la política cultural del Gobierno, dirigidas a preservar y potenciar realmente las diversas culturas del Estado $y$, al mismo tiempo, distribuir equitativamente los recursos públicos.

Situación actual: Concluido (Formulado Pleno) en fecha 03 Nov 1999. 
Procedimiento: Ordinario.

Fecha de presentación: 25/10/99.

Autor: Arévalo Santiago, Juan Antonio (GPS)

Objeto: Interpelación sobre si el Gobierno ha interesado al Ministerio Fiscal determinadas iniciativas, así como sobre cualquier otra intervención que haya podido llevar a cabo en relación con el asunto que instruyó el señor Gómez de Liaño.

Situación actual: Concluido (No admitido) en fecha 26 Oct 1999.

Procedimiento: Ordinario.

Fecha de presentación: 25/10/99.

Autores: Torres Cardona, Isidoro (GPMX). Cámara Fernández, Manuel (GPMX).

Objeto: Interpelación sobre la forma en la que se desarrolla y controla el proceso de información electoral a los integrantes del Censo de Españoles Residentes Ausentes (CERA), así como sobre las medidas a adoptar encaminadas a garantizar la nitidez total y absoluta en los procesos electorales.

Situación actual: Concluido (Formulado Pleno) en fecha 03 Nov 1999.

Procedimiento: Ordinario.

Fecha de presentación: 4/11/99.

Autor: Cámara Fernández, Manuel (GPMX).

Objeto: Interpelación sobre la política del Gobierno acerca de las retribuciones del personal funcionario y laboral de la Administración General del Estado, Administración Tributaria y Administración de Justicia, en relación con la especificidad que supone el hecho insular.

Situación actual: Concluido (Formulado Pleno) en fecha 17 Nov 1999.

Procedimiento: Ordinario.

Fecha de presentación: 22/11/99.

Autor: Zamorano Vázquez, Francisco José (GPS)

Objeto: Interpelación sobre la política sanitaria del Gobierno.

Situación actual: Concluido (Formulado Pleno) en fecha 01 Dic 1999. 
Procedimiento: Ordinario.

Fecha de presentación: 22/11/99.

Autor: Granado Martínez, Octavio José (GPS)

Objeto: Interpelación sobre las medidas a adoptar por el Gobierno en materia de regulación legal de los incentivos a personal directivo de las empresas, de tratamiento fiscal de estas rentas, de transparencia y publicidad de estas decisiones, y sobre los requisitos que deben cumplir las sociedades que apliquen estos mecanismos de retribución.

Situación actual: Concluido (Formulado Pleno) en fecha 01 Dic 1999.

\section{B.IV. Mociones consecuencia de interpelación}

Referenciamos de esta categoría algunas de las más significativas, de entre las 13 presentadas, aún habiendo sido rechazadas algunas de ellas.

\section{Moción consecuencia de interpelación}

Procedimiento: Ordinario.

Fecha de presentación: 16/09/99.

Autor: Grupo Parlamentario Socialista.

Objeto: Moción por la que se insta al Gobierno a que reoriente los procesos de liberalización que no están dando resultados en forma de introducción efectiva de competencia, $y$ a que estudie e instrumente medidas para evitar que determinadas empresas evolucionen hacia situaciones de oligopolio.

Situación actual: Concluido (Rechazado) en fecha 28 Sep 1999.

Procedimiento: Ordinario.

Fecha de presentación: 7/10/99.

Autor: Grupo Parlamentario Socialista.

Objeto: Moción por la que se insta al Gobierno a establecer una tarifa plana para el acceso de los prestadores de servicios de Internet, a exigir a los operadores el correcto funcionamiento y mantenimiento de la red, a facilitar la implantación de nuevos operado- 
res, a garantizar que éstos no facturen las conexiones fallidas y apliquen correctamente las tarifas reducidas vigentes, a favorecer la diversificación de la oferta tecnológica y a subvencionar en todos los centros educativos y sanitarios la instalación de la tecnología ADSL o de otras que pudieran mejorar su calidad.

Situación actual: Concluido (Rechazado) en fecha 19 Oct 1999.

Procedimiento: Ordinario.

Fecha de presentación: 20/10/99.

Autor: Grupo Parlamentario Socialista.

Objeto: Moción por la que se insta al Gobierno a la elaboración y aplicación de un plan especial para la lucha contra la delincuencia y el incremento de la seguridad ciudadana en la provincia de Málaga.

Situación actual: Concluido (Rechazado) en fecha 02 Nov 1999.

Procedimiento: Ordinario.

Fecha de presentación: 20/10/99.

Autor: Grupo Parlamentario Socialista.

Objeto: Moción por la que se insta al Gobierno a que lidere todas las iniciativas necesarias en el seno de la Unión Europea para defender los elementos esenciales de la vigente Organización Común de Mercado (OCM) del plátano.

Situación actual: Concluido (Aprobado con modificaciones) en fecha 02 Nov 1999.

Procedimiento: Ordinario.

Fecha de presentación: 3/11/99.

Autor: Grupo Parlamentario Catalán en el Senado de Convergencia I Unió

Objeto: Moción por la que se insta al Gobierno a que materialice reglamentariamente los acuerdos adoptados por la Comisión Especial creada en el seno del Consejo del Patrimonio Artístico, con el fin de que puedan servir eficazmente a los fines por los que fueron adoptados.

Situación actual: Concluido (Rechazado) en fecha 16 Nov 1999. 
Procedimiento: Ordinario.

Fecha de presentación: 4/11/99.

Autor: Grupo Parlamentario Socialista.

Objeto: Moción por la que se insta al Gobierno a modificar la Ley General de Sanidad, a establecer controles adecuados para el cumplimiento de la Directiva 94/27/CE del Parlamento Europeo, a valorar la situación del ejercicio profesional del tatuaje, el "piercing" y la micropigmentación a fin de establecer un código de buenas prácticas que tenga como objetivo la prevención de riesgos y la protección de la salud, y a impulsar la formación profesional de este sector.

Situación actual: Concluido (Aprobado con modificaciones) en fecha 16 Nov 1999.

Procedimiento: Ordinario..

Fecha de presentación: 4/11/99..

Autor: Grupo Parlamentario Mixto.

Objeto: Moción por la que se insta al Gobierno a que adopte las medidas necesarias a fin de que evite el uso perverso de la actual redacción del artículo tercero de la Orden Ministerial de 24 de abril de 1996, el cual permite el voto de cualquier ciudadano sin garantizar el vínculo de la unión de éste con la circunscripción en la cual solicita votar.

Situación actual: Concluido (Rechazado) en fecha 16 Nov 1999.

Procedimiento: Ordinario.

Fecha de presentación: 18/11/99.

Autor: Grupo Parlamentario Socialista.

Objeto: Moción por la que se insta al Gobierno a remitir a las Cortes Generales, antes de finalizar la presente Legislatura, el Plan Director de la Cooperación Internacional para el Desarrollo que contempla la Ley 23/1998, de 7 de julio, en su artículo octavo, así como los reglamentos dictaminados por el Consejo de Cooperación y que desarrollan dicha Ley.

Situación actual: Concluido (Aprobado sin modificaciones) en fecha 30 Nov 1999. 
Procedimiento: Ordinario.

Fecha de presentación: 18/11/99.

Autor: Grupo Parlamentario Mixto.

Objeto: Moción por la que se insta al Gobierno a que tome las medidas necesarias para que se reconozca el derecho a percibir el complemento por residencia, en iguales condiciones, para el personal funcionario y laboral de la Administración General del Estado, de la Administración Tributaria y de la Administración de Justicia en la Comunidad Autónoma de las Illes Balears equiparando, al mismo tiempo, dicho complemento al de la Comunidad Autónoma de Canarias, Ceuta y Melilla.

Situación actual: Concluido (Aprobado con modificaciones) en fecha 30 Nov 1999.

\section{B.V. Preguntas orales en Pleno}

Fueron 105 las preguntas orales que se formularon ante el Pleno durante el presente período de Sesiones, por lo que no vamos a proceder a reflejarlas.

\section{B.VI. Preguntas orales en Comisión}

Fueron 64 las formuladas en Comisión, por lo que no se procede a su referencia puntual.

\section{B.VII. Preguntas orales en Comisión Mixta}

Las únicas preguntas formuladas en el seno de la Comisión Mixta fueron las 4 siguientes:

\section{Pregunta oral en Comisión Mixta formulada por Diputados}

Procedimiento: Ordinario.

Fecha de presentación: 15/09/99.

Autor: Camilleri Hernández, María José (GP) 
Objeto: Pregunta sobre las medidas adoptadas por el Gobierno para desmantelar las mafias que introducen mujeres inmigrantes indocumentadas en España.

Situación actual: Concluido (Caducado) en fecha 18 Ene 2000.

Comisión competente: Comisión Mixta de los Derechos de la Mujer.

Procedimiento: Ordinario.

Fecha de presentación: 15/09/99.

Autor: Camilleri Hernández, María José (GP)

Objeto: Pregunta sobre los proyectos y actuaciones llevadas a cabo por

el Gobierno para lograr la inserción social y elevar el nivel cultural de la mujer gitana.

Situación actual: Concluido (Convertido) en fecha 31 Dic 1999.

Comisión competente: Comisión Mixta de los Derechos de la Mujer.

Procedimiento: Ordinario.

Fecha de presentación: 15/09/99.

Autor: Camilleri Hernández, María José (GP)

Objeto: Pregunta sobre las actuaciones previstas por el Gobierno para facilitar la integración social de las mujeres emigrantes retornadas a España.

Situación actual: Concluido (Caducado) en fecha 18 Ene 2000.

Comisión competente: Comisión Mixta de los Derechos de la Mujer.

Procedimiento: Ordinario.

Fecha de presentación: 30/09/99.

Autor: Guardans I Cambó, Ignasi (GC-CIU)

Objeto: Pregunta sobre la oposición del Gobierno a la conversión en reglamento comunitario de los diversos convenios europeos de cooperación judicial en materia civil.

Situación actual: Concluido (Contestado) en fecha 23 Nov 1999.

Comisión competente: Comisión Mixta para la Unión Europea.

\section{B.VIII. Pregunta con respuesta escrita}

Se presentaron 1.663 preguntas con respuesta escrita durante el período de sesiones que venimos reseñando. 


\section{COMPETENCIAS ELECTIVAS}

\section{Elección del Defensor del Pueblo}

Procedimiento: Ordinario.

Fecha de presentación: 1/12/99.

Autor: Congreso de los Diputados.

Objeto: Comunicación de la expiración del plazo de nombramiento de D. Fernando Álvarez de Miranda y Torres como Defensor del Pueblo y de la declaración de vacante de dicho cargo, de conformidad con lo dispuesto en el artículo 5.2 de la Ley Orgánica 3/1981, de 6 de abril, del Defensor del Pueblo.

Situación actual: Concluido (Trasladado a la VII Legislatura) en fecha 18 Ene 2000.

Comisión competente: Comisión Mixta de Relaciones con el Defensor del Pueblo.

\section{DECLARACIONES INSTITUCIONALES}

\section{Declaración institucional}

Procedimiento: Ordinario.

Fecha de presentación: 15/09/99.

Autor: Presidencia del Senado.

Objeto: Declaración institucional sobre la grave situación en la que se encuentra la población de Timor Oriental.

Situación actual: Concluido (Aprobado) en fecha 15 Sep 1999.

Procedimiento: Ordinario.

Fecha de presentación: 1/12/99.

Autor: Presidencia del Senado.

Objeto: Declaración institucional del Senado con motivo del Día Internacional del Síndrome de Inmunodeficiencia Adquirida (SIDA).

Situación actual: Concluido (Aprobado) en fecha 01 Dic 1999.

Procedimiento: Ordinario.

Fecha de presentación: 17/12/99. 
Autor: Presidencia del Senado.

Objeto: Declaración institucional sobre la situación en Kosovo.

Situación actual: Concluido (Aprobado) en fecha 17 Dic 1999.

\section{E. RELACIONES CON ÓRGANOS E INSTITUCIONES PÚBLICAS}

\section{E.I. Con el Tribunal Constitucional}

\section{E.I.1. Recurso de inconstitucionalidad}

\section{Recurso de inconstitucionalidad}

Procedimiento: Ordinario.

Fecha de presentación: 17/09/99.

Documento que abre el expediente: $N .^{\circ}$ de registro 63603 de 17 de Septiembre de 1999 calificado (28/Sep/1999).

Autor: Tribunal Constitucional

Objeto: Recurso de inconstitucionalidad número 3547/1999, interpuesto por el Presidente del Gobierno, contra los artículos 217, 220.2, salvo el inciso relativo a vertidos al mar, 224.1 a) y 228.3 a) de la Ley 9/1999, de 13 de mayo, de Ordenación del Territorio de Canarias.

Situación actual: Concluido (Tramitado) en fecha 28 Sep 1999.

Procedimiento: Ordinario.

Fecha de presentación: 17/09/99.

Documento que abre el expediente: N. ${ }^{\circ}$ de registro 63604 de 17 de Septiembre de 1999 calificado (28/Sep/1999)

Autor: Tribunal Constitucional.

Objeto: Recurso de inconstitucionalidad número 3446/1999, interpuesto por el Abogado del Estado, en nombre del Presidente del Gobierno, contra diversos artículos de la Ley de Castilla-La Mancha 6/1999, de 15 de abril, de protección de la calidad del suministro eléctrico.

Situación actual: Concluido (Tramitado) en fecha 28 Sep 1999. 
Procedimiento: Ordinario.

Fecha de presentación: 17/09/99.

Documento que abre el expediente: N. ${ }^{\circ}$ de registro 63605 de 17 de Septiembre de 1999 calificado (28/Sep/1999).

Autor: Tribunal Constitucional.

Objeto: Recurso de inconstitucionalidad número 3536/1999, interpuesto por el Abogado del Estado, en nombre del Presidente del Gobierno, contra la Disposición Adicional Segunda y Disposición Transitoria Segunda, apartados $10^{\circ}$ y $3 .^{\circ}$, de la Ley del Parlamento de Canarias 8/1999, de 27 de abril, de creación de las escalas de Profesores Numerarios y Maestros de Taller de Formación Profesional Marítimo-Pesquera.

Situación actual: Concluido (Tramitado) en fecha 28 Sep 1999.

Procedimiento: Ordinario.

Fecha de presentación: 20/09/99.

Documento que abre el expediente: N. ${ }^{\circ}$ de registro 63644 de 20 de Septiembre de 1999 calificado (28/Sep/1999).

Autor: Tribunal Constitucional.

Objeto: Recurso de inconstitucionalidad número 3537/1999, interpuesto por el Abogado del Estado, en nombre del Presidente del Gobierno, contra los artículos 4.3, 20, 23.1 y 45.b), en relación con el artículo 46 de la Ley 5/1999, de 21 de mayo, de ordenación farmacéutica de Galicia.

Situación actual: Concluido (Tramitado) en fecha 28 Sep 1999.

Procedimiento: Ordinario.

Fecha de presentación: 20/09/99.

Documento que abre el expediente: N. ${ }^{\circ}$ de registro 63645 de 20 de Septiembre de 1999 calificado (28/Sep/1999).

\section{(EXPEDIENTE RELACIONADO CON OTROS)}

Autor: Tribunal Constitucional.

Objeto: Recurso de inconstitucionalidad número 3247/1999, promovido por Dña. Soledad Mestre García, en representación de ochenta y 
dos Diputados del Grupo Parlamentario Socialista, contra la Ley 13/1999, de 21 de abril, de adhesión de España a diversos acuerdos del Fondo Monetario Internacional y, en especial, sus artículos 2 y 3.

Situación actual: Concluido (Tramitado) en fecha 28 Sep 1999.

Procedimiento: Ordinario.

Fecha de presentación: 6/10/99.

Documento que abre el expediente: $\mathrm{N}^{\circ}$ de registro 64469 de 06 de Octubre de 1999 calificado (13/0ct/1999).

Autor: Tribunal Constitucional.

Objeto: Sentencia dictada por el Pleno del Tribunal Constitucional en el recurso de inconstitucionalidad número 433/1994, promovido por el Presidente del Gobierno contra el artículo 10.3 de la Ley 12/1993, de 4 de noviembre, del Parlamento de Cataluña, de creación del Instituto para el Desarrollo de las Comarcas del Ebro (se corresponde con el número de expediente $752 / 000025$ de la V Legislatura).

Situación actual: Concluido (Tramitado) en fecha 13 Oct 1999.

Procedimiento: Ordinario.

Fecha de presentación: 17/11/99.

Documento que abre el expediente: N. ${ }^{\circ}$ de registro 66000 de 17 de Noviembre de 1999 calificado (23/Nov/1999).

Autor: Tribunal Constitucional.

Objeto: Sentencia dictada por el Pleno del Tribunal Constitucional en el recurso de inconstitucionalidad número 1840/1989, promovido por el Presidente del Gobierno contra determinados preceptos de la Ley Foral de Navarra 7/1989, de 8 de junio, de medidas de intervención en materia de suelo y vivienda (se corresponde con el número de expediente 752/000165 de la III Legislatura).

Situación actual: Concluido (Tramitado) en fecha 23 Nov 1999.

Procedimiento: Ordinario.

Fecha de presentación: 17/11/99.

Documento que abre el expediente: N. ${ }^{\circ}$ de registro 66001 de 17 de Noviembre de 1999 calificado (23/Nov/1999). 
Autor: Tribunal Constitucional.

Objeto: Sentencia dictada por el Pleno del Tribunal Constitucional en los recursos de inconstitucionalidad acumulados números $2009 / 1989$ y 2027/1989, promovidos, respectivamente, por el Gobierno Vasco y el Gobierno de la Generalidad de Cataluña contra determinados preceptos de la Ley 16/1989, de 17 de julio, de Defensa de la Competencia (se corresponde con los números de expediente 752/000004 y 752/000003 de la IV Legislatura).

Situación actual: Concluido (Tramitado) en fecha 23 Nov 1999.

Procedimiento: Ordinario.

Fecha de presentación: 3/12/99.

Documento que abre el expediente: N. ${ }^{\circ}$ de registro 67007 de 03 de Diciembre de 1999 calificado (13/Dic/1999).

Autor: Tribunal Constitucional.

Objeto: Recurso de inconstitucionalidad número 4596/1999, promovido por el Presidente del Gobierno, en relación con el párrafo primero del artículo 19.2 de la Ley del Parlamento de Cataluña 8/1988, en la redacción dada al mismo por la Ley 9/1999, de 30 de julio, de apoyo a las selecciones catalanas.

Situación actual: Concluido (Tramitado) en fecha 13 Dic 1999.

Procedimiento: Ordinario.

Fecha de presentación: 23/12/1999

Documento que abre el expediente: $\mathrm{N} .^{\circ}$ de registro 67567 de 23 de Diciembre de 1999 calificado (20/Ene/2000).

Autor: Tribunal Constitucional.

Objeto: Sentencia dictada por el Pleno del Tribunal Constitucional en el recurso de inconstitucionalidad número 2514/1994, promovido por el Gobierno de la Generalidad de Cataluña, contra determinados preceptos de la Ley 3/1994, de 14 de abril, que adapta la legislación española en materia de entidades de crédito a la Segunda Directiva de Coordinación Bancaria y se introducen otras modificaciones relativas al sistema financiero (se corresponde con el número de expediente de la $\mathrm{V}$ Legislatura 752/000035).

Situación actual: Concluido (Tramitado) en fecha 20 Ene 2000. 


\section{E.I.2. Cuestión de inconstitucionalidad}

\section{Cuestión de inconstitucionalidad}

Procedimiento: Ordinario.

Fecha de presentación: 22/09/99

Documento que abre el expediente: N. ${ }^{\circ}$ de registro 63763 de 22 de Septiembre de 1999 calificado (28/Sep/1999).

Autor: Tribunal Constitucional.

Objeto: Cuestión de inconstitucionalidad número 1780/1999, planteada por el Jugado de Primera Instancia número 46 de Madrid, por supuesta inconstitucionalidad del artículo 150.2 del Real Decreto Legislativo 1/1996, de 12 de abril, por el que se aprueba el Texto Refundido de la Ley de Propiedad Intelectual, en la reordenación efectuada por la Ley $5 / 1998$, de 6 de marzo, de incorporación al Derecho español de la Directiva 96/9/CE, de 11 de marzo de 1996, sobre protección jurídica de las bases de datos, por posible contradicción con los artículos 9.3, 66.2 y 82 de la Constitución.

Situación actual: Concluido (Tramitado) en fecha 28 Sep 1999.

Procedimiento: Ordinario.

Fecha de presentación: 22/09/99.

Documento que abre el expediente: N. ${ }^{\circ}$ de registro 63764 de 22 de Septiembre de 1999 calificado (28/Sep/1999).

Autor: Tribunal Constitucional.

Objeto: Cuestión de inconstitucionalidad número 3206/1999, planteada por el Jugado de Primera Instancia e Instrucción número 3 de Logroño, en relación con el artículo 1.2 (así como los apartados 1 y 7 del punto primero del Anexo) del Decreto 632/1968, de 21 de marzo, por el que se aprueba el Texto Refundido de la Ley sobre Responsabilidad Civil y Seguro de la Circulación de Vehículos a Motor, en la redacción dada por la Disposición Adicional Octava de la Ley 30/1995, de 8 de noviembre, de Ordenación y Supervisión de los Seguros Privados.

Situación actual: Concluido (Tramitado) en fecha 28 Sep 1999.

Procedimiento: Ordinario.

Fecha de presentación: 22/09/99. 
Documento que abre el expediente: $N .^{\circ}$ de registro 63765 de 22 de Septiembre de 1999 calificado (28/Sep/1999).

Autor: Tribunal Constitucional.

Objeto: Cuestión de inconstitucionalidad número 3066/1999, planteada por la Sección Novena de la Sala de lo Contencioso-Administrativo del Tribunal Superior de Justicia de Madrid, en relación con la Ley de la Comunidad de Madrid, 4/1994, de 6 de junio, de Calendario y Horario Comerciales, por posible vulneración de los artículos 149.1.13. ${ }^{\mathrm{a}}$ y 149.3 de la Constitución Española.

Situación actual: Concluido (Tramitado) en fecha 28 Sep 1999.

Procedimiento: Ordinario.

Fecha de presentación: 22/09/99.

Documento que abre el expediente: N. ${ }^{\circ}$ de registro 63766 de 22 de Septiembre de 1999 calificado (28/Sep/1999).

Autor: Tribunal Constitucional.

Objeto: Cuestión de inconstitucionalidad número 3065/1999, planteada por la Sección Novena de la Sala de lo Contencioso-Administrativo del Tribunal Superior de Justicia de Madrid (recurso número 2453/1994), en relación con la Ley de la Comunidad de Madrid, 4/1994, de 6 de junio, de Calendario y Horario Comerciales, por posible vulneración de los artículos 149.1.13. ${ }^{\mathrm{a}}$ y 149.3 de la Constitución.

Situación actual: Concluido (Tramitado) en fecha 28 Sep 1999.

\section{Procedimiento: Ordinario.}

Fecha de presentación: 22/09/99.

Documento que abre el expediente: N. ${ }^{\circ}$ de registro 63767 de 22 de Septiembre de 1999 calificado (28/Sep/1999).

Autor: Tribunal Constitucional.

Objeto: Cuestión de inconstitucionalidad número 3207/1999, planteada por el Juzgado de Primera Instancia e Instrucción número 3 de Logroño, en relación con el artículo 1.2 (así como apartados 1 y 7 del punto primero del Anexo) del Decreto 632/1968, de 21 de marzo, por el que se aprueba el Texto Refundido de la Ley sobre Responsabilidad Civil y Seguro de la Circulación de Vehículos a Motor, en la redacción dada por la Disposición Adicional Octava 
de la Ley 30/1995, de 8 de noviembre, de Ordenación y Supervisión de los Seguros Privados.

Situación actual: Concluido (Tramitado) en fecha 28 Sep 1999.

Procedimiento: Ordinario.

Fecha de presentación: 18/10/99.

Documento que abre el expediente: N. ${ }^{\circ}$ de registro 64811 de 18 de Octubre de 1999 calificado (02/Nov/1999).

Autor: Tribunal Constitucional.

Objeto: Cuestión de inconstitucionalidad número 3899/1999, planteada por el Juzgado de Primera Instancia número 5 de Oviedo, respecto del artículo 31.4 de la Ley de Arrendamientos Urbanos de 1964, en la redacción dada por el artículo 19 de la Ley 19/1989, de 25 de julio, y posterior redacción por la Disposición 13. ${ }^{a}$ del Real Decreto-Ley $7 / 1989$, de 29 de diciembre, confirmado por la Disposición adicional 10. ${ }^{a}$ de la Ley 5/1990, de 29 de junio.

Situación actual: Concluido (Tramitado) en fecha 02 Nov 1999.

Procedimiento: Ordinario.

Fecha de presentación: 18/10/99.

Documento que abre el expediente: $\mathrm{N}^{\circ}$ de registro 64812 de 18 de Octubre de 1999 calificado (02/Nov/1999).

Autor: Tribunal Constitucional.

Objeto: Cuestión de inconstitucionalidad número 3995/1999, planteada por la Sección Séptima de la Audiencia Provincial de Sevilla, respecto del apartado $1 .^{\circ}$ de la Disposición adicional decimoctava de la Ley 46/1985, de 27 de diciembre, de Presupuestos Generales del Estado para 1986.

Situación actual: Concluido (Tramitado) en fecha 02 Nov 1999.

Procedimiento: Ordinario.

Fecha de presentación: 3/12/99.

Documento que abre el expediente: $\mathrm{N} .^{\circ}$ de registro 67008 de 03 de Diciembre de 1999 calificado (13/Dic/1999).

Autor: Tribunal Constitucional.

Objeto: Cuestión de inconstitucionalidad número 4795/1999, que plantea la Sala de lo Contencioso-Administrativo, en Santa Cruz de 
Tenerife, del Tribunal Superior de Justicia de Canarias, por supuesta inconstitucionalidad del artículo 41 de la Ley 39/1988, de 28 de diciembre, de Haciendas Locales, en los particulares que se refieren a prestaciones patrimoniales de carácter público, por cuanto la referida disposición, puesta en colación con los artículos 45,48 y 117 de la misma Ley, pudiera ser contraria al artículo 31.3 de la Constitución.

Situación actual: Concluido (Tramitado) en fecha 13 Dic 1999.

Procedimiento: Ordinario.

Fecha de presentación: 20/12/99.

Documento que abre el expediente: $\mathrm{N}{ }^{\circ}$ de registro 67496 de 20 de Diciembre de 1999 calificado (20/Ene/2000).

Autor: Tribunal Constitucional.

Objeto: Cuestión de inconstitucionalidad número 2177/1998, que plantea la Sala de lo Social del Tribunal Superior de Justicia de las Islas Baleares, por supuesta inconstitucionalidad del artículo 6.6 de la Ley 5/1996, de 18 de diciembre, de la Comunidad Autónoma de las Islas Baleares, de Medidas Tributarias y Administrativas, por poder vulnerar los artículos 9.3, 14, 33.3 y 37.1 de la Constitución.

Situación actual: Concluido (Tramitado) en fecha 20 Ene 2000.

Procedimiento: Ordinario.

Fecha de presentación: 23/12/99.

Documento que abre el expediente: $\mathrm{N}^{\circ}$ de registro 67565 de 23 de Diciembre de 1999 calificado (20/Ene/2000).

Autor: Tribunal Constitucional.

Objeto: Sentencia dictada por el Pleno del Tribunal Constitucional en la cuestión de inconstitucionalidad número 1413/1994, que fue planteada por la Sección Tercera de la Sala de lo ContenciosoAdministrativo del Tribunal Superior de Justicia del País Vasco, respecto de la Disposición adicional vigésima de la Ley 37/1988, de Presupuestos Generales del Estado para 1989 (se corresponde con el número de expediente de la $\mathrm{V}$ Legislatura 753/000095).

Situación actual: Concluido (Tramitado) en fecha 20 Ene 2000. 


\section{E.II. Con el Poder Judicial}

E.Il.1. Memoria del Consejo General del Poder Judicial.

\section{Memoria del Consejo General del Poder Judicial}

Procedimiento: Ordinario.

Fecha de presentación: 21/10/99.

Autor: Consejo General del Poder Judicial.

Objeto: Memoria correspondiente al año 1998 sobre el estado, funcionamiento y actividades del Consejo General del Poder Judicial y de los Juzgados y Tribunales de Justicia, aprobada por el Pleno de dicho Consejo en su sesión del día 21 de julio de 1999, así como la relación circunstanciada de necesidades para el año 2000, aprobada por el Pleno el día 22 de septiembre de 1999.

Situación actual: Concluido en fecha 21 Dic 1999.

Comisión competente: Comisión de Justicia.

E.Il.2 Otras manifestaciones de relación con el Consejo General del Poder Judicial.

Otras manifestaciones de relación con el Consejo General del Poder Judicial

Procedimiento: Ordinario.

Fecha de presentación: 5/10/99.

Autor: Consejo General del Poder Judicial.

Objeto: Comunicación del acuerdo adoptado por el Pleno del Consejo General del Poder Judicial, en su sesión del día 22 de septiembre de 1999, mediante el que se aprueba la relación circunstanciada de necesidades para el año 2000.

Situación actual: Concluido (Tramitado) en fecha 13 Oct 1999.

E.Il.3. Otros asuntos relacionados con órganos jurisdiccionales

Otros asuntos relacionados con órganos jurisdiccionales

Procedimiento: Ordinario.

Fecha de presentación: 22/10/99. 
Autor: Tribunal Supremo.

Objeto: Certificación del Acuerdo, con voto particular, adoptado por la Sala de Gobierno del Tribunal Supremo, en sesión celebrada el día 4 de octubre de 1999, por el que se estima necesario y urgente, para la debida eficacia del trabajo de sus Magistrados en el cumplimiento de sus funciones, el aumento del número de letrados que actualmente componen su gabinete técnico.

Situación actual: Concluido (Tramitado) en fecha 02 Nov 1999.

\section{E.III. Con el Tribunal de Cuentas}

\section{E.III.1. Informe sobre la Cuenta General del Estado}

\section{Informe sobre la Cuenta General del Estado}

Procedimiento: Ordinario.

Fecha de presentación: 26/11/99.

Autor: Tribunal de Cuentas.

Objeto: Declaración Definitiva sobre la Cuenta General del Estado correspondiente al ejercicio de 1997, aprobada por el Pleno del Tribunal de Cuentas en su sesión del día 24 de noviembre de 1999, así como su fundamentación y desarrollo.

Situación actual: Concluido (Trasladado a la VII Legislatura) en fecha 18 Ene 2000.

Comisión competente: Comisión Mixta para las Relaciones con el Tribunal de Cuentas.

\section{E.III.2. Otros informes del Tribunal de Cuentas}

Reseñamos algunos de los 14 informes presentados por el Tribunal de Cuentas.

Procedimiento: Ordinario.

Fecha de presentación: 1/10/99.

Autor: Tribunal de Cuentas.

Objeto: Informe de fiscalización del Consejo Superior de Deportes (CSD), ejercicio 1996, aprobado por el Pleno del Tribunal de Cuentas en su sesión del día 29 de septiembre de 1999. 
Situación actual: Concluido (Trasladado a la VII Legislatura) en fecha 18 Ene 2000.

Comisión competente: Comisión Mixta para las Relaciones con el Tribunal de Cuentas.

Procedimiento: Ordinario.

Fecha de presentación: 1/10/99.

Autor: Tribunal de Cuentas.

Objeto: Informe de fiscalización sobre las principales actuaciones del ente público Red Técnica Española de Televisión (RETEVISIÓN) en 1996, relativas al proceso de privatización de RETEVISIÓN, S.A., aprobado por el Pleno del Tribunal de Cuentas en su sesión del día 29 de septiembre de 1999.

Situación actual: Concluido (Trasladado a la VII Legislatura) en fecha 18 Ene 2000.

Comisión competente: Comisión Mixta para las Relaciones con el Tribunal de Cuentas.

Procedimiento: Ordinario.

Fecha de presentación: 8/10/99.

Autor: Tribunal de Cuentas.

Objeto: Informe de fiscalización de la Tesorería General de la Seguridad Social, ejercicio de 1996, aprobado por el Pleno del Tribunal de Cuentas en su sesión del día 29 de septiembre de 1999.

Situación actual: Concluido (Trasladado a la VII Legislatura) en fecha 18 Ene 2000.

Comisión competente: Comisión Mixta para las Relaciones con el Tribunal de Cuentas.

Procedimiento: Ordinario.

Fecha de presentación: 2/11/99.

Autor: Tribunal de Cuentas.

Objeto: Informe de fiscalización de las inversiones realizadas por el Instituto para la Diversificación y el Ahorro de la Energía (IDEA), ejercicios 1995-1996, aprobado por el Pleno del Tribunal de Cuentas en su sesión del día 27 de octubre de 1999. 
Situación actual: Concluido (Trasladado a la VII Legislatura) en fecha 18 Ene 2000.

Comisión competente: Comisión Mixta para las Relaciones con el Tribunal de Cuentas.

Procedimiento: Ordinario.

Fecha de presentación: 25/11/99.

Autor: Tribunal de Cuentas.

Objeto: Informe de fiscalización de la actividad de la sociedad estatal

Patrimonio I (actualmente Sociedad Estatal de Participaciones

Patrimoniales), en 1995 y 1996 (OPV de Argentaria, S.A. y Telefónica, S.A.), aprobado por el Pleno del Tribunal de Cuentas en su sesión del día 24 de noviembre de 1999.

Situación actual: Concluido (Trasladado a la VII Legislatura) en fecha 18 Ene 2000.

Comisión competente: Comisión Mixta para las Relaciones con el Tribunal de Cuentas.

Procedimiento: Ordinario.

Fecha de presentación: 29/11/99.

Autor: Tribunal de Cuentas.

Objeto: Informe de fiscalización de la contabilidad de los partidos políticos, ejercicio 1996, aprobado por el Pleno del Tribunal de Cuentas en su sesión del día 24 de noviembre de 1999.

Situación actual: Concluido (Trasladado a la VII Legislatura) en fecha 18 Ene 2000.

Comisión competente: Comisión Mixta para las Relaciones con el Tribunal de Cuentas.

Procedimiento: Ordinario.

Fecha de presentación: 23/12/99.

Autor: Tribunal de Cuentas.

Objeto: Informe de fiscalización del Instituto de la Cinematografía y de las Artes Audiovisuales, ejercicio 1996, aprobado por el Pleno del Tribunal de Cuentas en su sesión del día 21 de diciembre de 1999.

Situación actual: Concluido (Trasladado a la VII Legislatura) en fecha 18 Ene 2000. 
E.III.3. Otras manifestaciones de relación con el Tribunal de Cuentas.

De los 10 informes presentados por el Tribunal de Cuentas, reseñaremos los siguientes:

\section{Solicitudes de fiscalización del Tribunal de Cuentas}

Procedimiento: Ordinario.

Fecha de presentación: 25/11/99.

Documento que abre el expediente: $N .^{\circ}$ de registro 66484 -* $^{*}$ de 25 de Noviembre de 1999 calificado (13/Dic/1999).

Núm. Exp. Congreso: 253/000022

Autor: Grupo Socialista del Congreso.

Objeto: Solicitud de una fiscalización sobre la gestión económica, financiera, presupuestaria y contable, asi como sobre las contrataciones de la Diputación Provincial de Lugo y del Instituto Lucense de Desarrollo (INLUDES), en los ejercicios 1991 a 1995.

Situación actual: Concluido (Rechazado) en fecha 30 Nov 1999.

Procedimiento: Ordinario.

Fecha de presentación: 25/11/99.

Documento que abre el expediente: $N .^{\circ}$ de registro 66484 -* $^{*}$ de 25 de Noviembre de 1999 calificado (13/Dic/1999).

Núm. Exp. Congreso: 253/000024

Autor: Grupo Parlamentario Mixto del Congreso.

Objeto: Solicitud de una fiscalización sobre la gestión económica, presupuestaria y contable, así como sobre las contrataciones del Ayuntamiento de Benidorm (Alicante) y de las sociedades participadas por el mismo, entre los años 1991 a 1994.

Situación actual: Concluido (Rechazado) en fecha 30 Nov 1999.

Procedimiento: Ordinario.

Fecha de presentación: 25/11/99.

Documento que abre el expediente: N. ${ }^{\circ}$ de registro 66484 - $^{*}$ de 25 de Noviembre de 1999 calificado (13/Dic/1999). 
Núm. Exp. Congreso: 253/000027

Autor: Grupo Socialista del Congreso.

Objeto: Solicitud de una fiscalización integral sobre la gestión económica, presupuestaria, económico-financiera y patrimonial de la Agencia Española de Cooperación Internacional (AECI) y la gestión en cuanto a concesión, aplicación y justificación de las subvenciones concedidas entre los años 1996 a 1999.

Situación actual: Concluido (Rechazado) en fecha 30 Nov 1999.

Procedimiento: Ordinario.

Fecha de presentación: 25/11/99.

Documento que abre el expediente: $\mathrm{N}^{\circ}$ de registro $66484-{ }^{*}$ de 25 de Noviembre de 1999 calificado (13/Dic/1999).

Núm. Exp. Congreso: 253/000031

Autor: Grupo Socialista del Congreso.

Objeto: Solicitud de una fiscalización de la gestión económica, financiera, presupuestaria y contable, así como sobre las contrataciones de personal, de obras y servicios del Ayuntamiento de Carballedo (Lugo), correspondiente a los ejercicios de 1994 a 1998.

Situación actual: Concluido (Rechazado) en fecha 30 Nov 1999.

\section{E.IV. Con el Defensor del Pueblo}

No habiéndose presentado informe anual del Defensor del Pueblo en el presente periodo de sesiones, reseñaremos otros informes del Defensor del Pueblo.

\section{E.IV.1. Otros informes del Defensor del Pueblo}

\section{Otros informes del Defensor del Pueblo}

Procedimiento: Ordinario.

Fecha de presentación: 30/11/99.

Documento que abre el expediente: $\mathrm{N} .^{\circ}$ de registro 66611 -* $^{*}$ de 30 de Noviembre de 1999 calificado (13/Dic/1999).

Núm. Exp. Congreso: 261/000004 
Autor: Defensor del Pueblo.

Objeto: Informe relativo a residuos sólidos urbanos.

Situación actual: Concluido (Caducado) en fecha 18 Ene 2000.

Comisión competente: Comisión Mixta de Relaciones con el Defensor del Pueblo.

Procedimiento: Ordinario.

Fecha de presentación: 30/11/99.

Documento que abre el expediente: $\mathrm{N}_{*}^{\circ}$ de registro $66611-^{*}$ de 30 de Noviembre de 1999 calificado (13/Dic/1999).

Núm. Exp. Congreso: 261/000005

Autor: Defensor del Pueblo.

Objeto: Informe relativo a la asistencia geriátrica y gerontológica.

Situación actual: Concluido (Tramitado) en fecha 13 Dic 1999.

Procedimiento: Ordinario.

Fecha de presentación: 30/11/99.

Documento que abre el expediente: $\mathrm{N}^{\circ}$ de registro $66611^{*}$ de 30 de

Noviembre de 1999 calificado (13/Dic/1999).

Núm. Exp. Congreso: 261/000006

Autor: Defensor del Pueblo.

Objeto: Informe relativo a la violencia escolar.

Situación actual: Concluido (Tramitado) en fecha 13 Dic 1999.

Procedimiento: Ordinario.

Fecha de presentación: 30/11/99.

Documento que abre el expediente: $\mathrm{N}^{\circ}$ de registro 66611 -* $^{*}$ de 30 de Noviembre de 1999 calificado (13/Dic/1999).

Núm. Exp. Congreso: 261/000007

Autor: Defensor del Pueblo.

Objeto: Informe sobre determinadas propuestas de revisión de la Ley Orgánica 3/1981, de 6 de abril, del Defensor del Pueblo.

Situación actual: Concluido (Caducado) en fecha 18 Ene 2000.

Comisión competente: Comisión Mixta de Relaciones con el Defensor del Pueblo. 


\section{E.V. RELACIÓN CON ÓRGANOS DE LAS COMUNIDADES AUTÓNOMAS}

Por ser la Cámara de representación territorial, procedemos a referenciar, aun a riesgo de su extensión, las 12 manifestaciones de relación con órganos de las Comunidades Autónomas.

\section{Manifestaciones de relación con órganos de las Comunidades Autónomas}

Procedimiento: Ordinario.

Fecha de presentación: 28/09/99.

Documento que abre el expediente: $N .^{\circ}$ de registro 64055 de 28 de Septiembre de 1999 calificado (05/Oct/1999).

\section{(EXPEDIENTE RELACIONADO CON OTROS)}

Autor: Cortes de Aragón.

Objeto: Comunicación de la designación, en sesión plenaria celebrada el día 23 de septiembre de 1999, de D. Santiago Lanzuela Marina y D. Francisco Catalá Pardo como Senadores en representación de la Comunidad Autónoma de Aragón.

Situación actual: Concluido (Tramitado) en fecha 05 Oct 1999.

Procedimiento: Ordinario.

Fecha de presentación: 19/10/99.

Documento que abre el expediente: N. ${ }^{\circ}$ de registro 64840 de 19 de Octubre de 1999 calificado (02/Nov/1999).

Autor: Parlamento de Navarra.

Objeto: Certificación de la designación en sesión celebrada el día 7 de octubre de 1999, de D. Francisco Javier Sanz Carramiñana como Senador en representación de la Comunidad Foral de Navarra.

Situación actual: Concluido (Tramitado) en fecha 02 Nov 1999.

Procedimiento: Ordinario.

Fecha de presentación: 3/11/99.

Documento que abre el expediente: N. ${ }^{\circ}$ de registro 65527 de 03 de Noviembre de 1999 calificado (10/Nov/1999). 
Autores: Cortes de Castilla La Mancha. Junta General del Principado de Asturias.

Objeto: Resoluciones aprobadas por los Parlamentos de diversas Comunidades Autónomas relativas a la subida de las pensiones mínimas y no contributivas.

Situación actual: Concluido (Tramitado) en fecha 30 Nov 1999.

Procedimiento: Ordinario.

Fecha de presentación: 8/11/99.

Documento que abre el expediente: N. ${ }^{\circ}$ de registro 65763 de 08 de Noviembre de 1999 calificado (16/Nov/1999).

Autor: Parlamento de Cataluña.

Objeto: Comunicación de la constitución del Parlamento de Cataluña, en sesión celebrada el día 5 de noviembre de 1999.

Situación actual: Concluido (Tramitado) en fecha 10 Nov 1999.

Procedimiento: Ordinario.

Fecha de presentación: 11/11/99.

Documento que abre el expediente: N. ${ }^{\circ}$ de registro 65839 de 11 de Noviembre de 1999 calificado (23/Nov/1999).

Autor: Parlamento de la Rioja.

Objeto: Comunicación del cambio de denominación de la Diputación General de La Rioja que ha pasado a ser Parlamento de La Rioja, así como de la elección, con fecha 2 de julio de 1999, de D. José Ignacio Ceniceros González como Presidente de dicho Parlamento.

Situación actual: Concluido (Tramitado) en fecha 23 Nov 1999.

Procedimiento: Ordinario.

Fecha de presentación: 17/11/99.

Documento que abre el expediente: N. ${ }^{\circ}$ de registro 66004 de 17 de Noviembre de 1999 calificado (23/Nov/1999).

Autor: Parlamento de las illes Balears.

Objeto: Certificación acreditativa de la aprobación por el Pleno del Parlamento de las llles Balears, en su sesión del día 2 de noviembre de 1999, de la declaración institucional relativa al caso de Joaquín 
José Martínez, condenado a muerte por el Estado de Florida (Estados Unidos).

Situación actual: Concluido (Tramitado) en fecha 23 Nov 1999.

Procedimiento: Ordinario.

Fecha de presentación: 26/11/99.

Documento que abre el expediente: N. ${ }^{\circ}$ de registro 66496 de 26 de Noviembre de 1999 calificado (13/Dic/1999).

Autor: Asamblea de Extremadura.

Objeto: Certificación del acuerdo adoptado por el Pleno de la Asamblea de Extremadura, en sesión celebrada el día 11 de noviembre de 1999, por el que se rechaza, del Proyecto de Ley de Presupuestos Generales del Estado para el año 2000, las consignaciones destinadas a la Comunidad Autónoma de Extremadura.

Situación actual: Concluido (Tramitado) en fecha 13 Dic 1999.

Procedimiento: Ordinario.

Fecha de presentación: 29/11/99.

Documento que abre el expediente: N. ${ }^{\circ}$ de registro 66579 de 29 de Noviembre de 1999 calificado (13/Dic/1999).

\section{(EXPEDIENTE RELACIONADO CON OTROS)}

Autor: Parlamento de Navarra.

Objeto: Certificación de la resolución aprobada por el Pleno del Parlamento de Navarra, en sesión celebrada el día 24 de noviembre de 1999, por la que dicho Parlamento muestra su apoyo a la iniciativa legislativa popular que se tramita en el Congreso de los Diputados, para la reducción de la jornada laboral a treinta y cinco horas semanales.

Situación actual: Concluido (Tramitado) en fecha 13 Dic 1999.

Procedimiento: Ordinario.

Fecha de presentación: 3/12/99.

Documento que abre el expediente: $\mathrm{N} .^{\circ}$ de registro 66996 de 03 de Diciembre de 1999 calificado (13/Dic/1999). 


\section{(EXPEDIENTE RELACIONADO CON OTROS)}

Autor: Parlamento de Cataluña.

Objeto: Comunicación de la designación en sesión celebrada el día 1 de diciembre de 1999, de D. Joan María Roig i Grau, D. Domènec Sesmilo i Rius, D. Joan Horaci Simó i Burgués, D. Lluís Armet i Coma, D. Ramón Espasa i Oliver, D. Rafael Luna Vivas y D. Carles Bonet i Revés, como Senadores en representación de la Comunidad Autónoma de Cataluña.

Situación actual: Concluido (Tramitado) en fecha 13 Dic 1999.

Procedimiento: Ordinario.

Fecha de presentación: 14/12/99.

Documento que abre el expediente: N. ${ }^{\circ}$ de registro 67354 de 14 de Diciembre de 1999 calificado (20/Ene/2000).

Autor: Parlamento de Navarra.

Objeto: Declaración política aprobada por la Junta de Portavoces del Parlamento de Navarra, en su reunión del día 30 de noviembre de 1999, mediante la que se solicita el esclarecimiento del fallecimiento del cooperante vasco D. Iñigo Egiluz y del sacerdote colombiano D. Jorge Luis Mazo.

Situación actual: Concluido (Trasladado a la VII Legislatura) en fecha 20 Ene 2000.

Procedimiento: Ordinario.

Fecha de presentación: 17/12/99.

Documento que abre el expediente: N. ${ }^{\circ}$ de registro 67458 de 17 de Diciembre de 1999 calificado (20/Ene/2000).

\section{(EXPEDIENTE RELACIONADO CON OTROS)}

Autor: Asamblea de Madrid.

Objeto: Comunicación del acuerdo adoptado por la Mesa de la Asamblea de Madrid, en su reunión del día 3 de diciembre de 1999, por el que se solicita a las Secretarías Generales del Congreso de los Diputados y del Senado el acceso a sus respectivas bases de datos, sobre la base de la reciprocidad.

Situación actual: Concluido (Tramitado) en fecha 20 Ene 2000. 
Procedimiento: Ordinario.

Fecha de presentación: 27/12/99.

Documento que abre el expediente: $\mathrm{N}^{\circ}$ de registro 67603 de 27 de Diciembre de 1999 calificado (20/Ene/2000).

Autor: Consejo de Gobierno de la Junta de Andalucía.

Objeto: Remisión del comunicado del Foro de la Inmigración en Andalucía en apoyo a la aprobación de la Proposición de Ley Orgánica sobre derechos y libertades de los extranjeros en España y su integración social.

Situación actual: Concluido (Trasladado a la VII Legislatura) en fecha 20 Ene 2000.

\section{F. RELACIONES INTERNACIONALES}

Del presente capítulo, reseñamos los más representativos de los documentos que se tramitaron en el Senado.

\section{F.I. Unión Interparlamentaria}

\section{Unión Interparlamentaria}

Procedimiento: Ordinario.

Fecha de presentación: 15/11/99.

Documento que abre el expediente: N..$^{\circ}$ de registro 65865 de 15 de Noviembre de 1999 calificado (23/Nov/1999).

Autor: Presidente del Grupo Espñaol de la Unión Interparlamentaria.

Objeto: Resoluciones aprobadas en la 102. ${ }^{a}$ Conferencia de la Unión Interparlamentaria, celebrada en Berlín (Alemania) durante los días 10 a 16 de octubre de 1999.

Situación actual: Concluido (Tramitado) en fecha 23 Nov 1999.

\section{F.ll. Asamblea Parlamentaria del Consejo de Europa}

\section{Asamblea Parlamentaria del Consejo de Europa}

Procedimiento: Ordinario.

Fecha de presentación: 21/10/99. 
Documento que abre el expediente: $\mathrm{N}^{\circ}$ de registro 65035 de 21 de Octubre de 1999 calificado (02/Nov/1999).

Autor: Delegación Española de la Asamblea Parlamentaria del Consejo de Europa.

Objeto: Solicitud de autorización para que algún miembro de las Comisiones del Congreso de los Diputados y del Senado, competentes por razón de la materia, asista los días 25 y 26 de noviembre de 1999 al Forum para el Desarrollo Territorial Duradero del Continente Europeo, organizado por el Consejo de Europa.

Situación actual: Concluido (Tramitado) en fecha 02 Nov 1999.

\section{F.III. Otras instituciones parlamentarias internacionales}

\section{Otras instituciones parlamentarias internacionales}

Procedimiento: Ordinario.

Fecha de presentación: 10/09/99.

Documento que abre el expediente: N. ${ }^{\circ}$ de registro 63158 de 10 de Septiembre de 1999 calificado (14/Sep/1999).

Núm. Exp. Congreso: 279/000420.

Autor: Comisión Mixta para la Unión Europea.

Objeto: Solicitud de autorización para que una delegación de la Comisión Mixta para la Unión Europea integrada por seis de sus miembros asista a la XXI Conferencia de Órganos Especializados en Asuntos Comunitarios (COSAC) convocada para los días $11 \mathrm{y}$ 12 de octubre de 1999 en la ciudad de Helsinki (Finlandia).

Situación actual: Concluido (Tramitado) en fecha 21 Sep 1999.

Procedimiento: Ordinario.

Fecha de presentación: 10/09/99.

Documento que abre el expediente: $N .^{\circ}$ de registro 63159 de 10 de Septiembre de 1999 calificado (14/Sep/1999).

Núm. Exp. Congreso: 279/000419.

Autor: Comisión Mixta para la Unión Europea.

Objeto: Solicitud de autorización para que D. Guillermo Martínez Casañ, Portavoz del Grupo Parlamentario Popular en el Congreso en la Comisión Mixta para la Unión Europea, pueda asistir a la 
reunión de modificación del Reglamento de la Conferencia de Órganos Especializados en Asuntos Comunitarios (COSAC) que tendrá lugar el próximo día 20 de septiembre en Helsinki (Finlandia), y a la cual asistirá un representante de cada uno de los órganos especializados en asuntos de la Unión Europea de los Parlamentos de los Estados miembros.

Situación actual: Concluido (Tramitado) en fecha 21 Sep 1999.

Procedimiento: Ordinario.

Fecha de presentación: 13/09/99.

Documento que abre el expediente: N. ${ }^{\circ}$ de registro 63289 de 13 de Septiembre de 1999 calificado (21/Sep/1999).

Núm. Exp. Congreso: 277/000020

Autor: Delegación Española en la Asamblea Paralamentaria de la Organización sobre seguridad y Cooperación en Europa (OSCE)

Objeto: Solicitud de autorización para asistir al Seminario sobre "Nuevos riesgos y oportunidades: Minorías en el siglo XXI", que se celebrará en Antalya (Turquía) los días 29 y 30 de septiembre de 1999.

Situación actual: Concluido (Tramitado) en fecha 21 Sep 1999. 